\title{
Advances in the antimicrobial and therapeutic potential of siderophores
}

\author{
Marta Ribeiro $^{1} \cdot$ Manuel Simões $^{1}$ (D)
}

Received: 15 April 2019 / Accepted: 23 April 2019 / Published online: 4 May 2019

(c) Springer Nature Switzerland AG 2019

\begin{abstract}
The increasing bacterial resistance from antibiotic overuse has fostered the search for novel antimicrobial strategies. In particular, bacterial systems involving iron (Fe) uptake are studied to develop new therapeutics against infectious diseases, because iron is crucial for bacterial growth and is a main virulence factor for infection. Iron assimilation is commonly based on the production of siderophores, which are iron chelators produced to facilitate iron uptake. Siderophores are thus crucial for bacterial pathogenicity. Here we review the antimicrobial and therapeutic potential of siderophores. There are three main approaches for siderophore application in antimicrobial therapy: siderophore-mediated drug delivery, inhibition of siderophores biosynthesis and iron starvation by competitive chelation. Major advances on the use of siderophores as therapeutic agents for disease treatment are also presented.
\end{abstract}

Keywords Antimicrobial resistance $\cdot$ Bacterial infections $\cdot$ Biofilm $\cdot$ Drug delivery $\cdot$ Iron $\cdot$ Siderophores $\cdot$ Trojan Horse approach

\section{Introduction}

The increased resistance of bacterial pathogens against the available panel of antibacterial agents is contributing for a growing number of untreatable infections (Fischbach and Walsh 2009; Andersson and Hughes 2011). Therefore, new and efficient therapeutics are required, and the iron acquisition mechanisms could be an attractive target. Iron is crucial for microbial growth and survival. Under iron-deprived conditions, microorganisms survive through the production of siderophores, which are low molecular weight compounds with high affinity for ferric iron (Schalk et al. 2011; Javvadi et al. 2018). Siderophore-mediated drug delivery, a Trojan Horse strategy, is an ideal approach to circumvent membrane-associated drug resistance. Inhibition of the biosynthesis of siderophores that are crucial for bacterial survival under iron-limited conditions represents another promising approach. Depriving pathogenic bacteria from iron is

Manuel Simões

mvs@fe.up.pt

1 LEPABE - Laboratório de Engenharia de Processos, Ambiente, Biotecnologia e Energia, Faculdade de Engenharia da, Universidade do Porto, Porto, Portugal another potential antimicrobial strategy (Ferreras et al. 2005; Miller et al. 2009).

This review outlines some recent results on the development of antimicrobial drugs that can disturb the assimilation of iron by bacteria, interfering with iron metabolism through mechanisms different from the current antibiotics. This article is an abridged version of the chapter published by Ribeiro and Simões (2019) in the series Environmental Chemistry for a Sustainable World (https://www.springer. com/series/11480).

\section{Siderophore iron uptake system}

Iron is a transition metal that can exist in two oxidation states: Fe(III) and Fe(II) (Hider and Kong 2010; Saha et al. 2016). This metal has a significant role in some of the most vital enzymatic processes such as oxygen metabolism, DNA and RNA synthesis as well as in the biosynthesis of porphyrins, antibiotics, toxins, cytochromes, siderophores and aromatic compounds (Schalk et al. 2011; Saha et al. 2016). In the environment, under the presence of oxygen and at neutral $\mathrm{pH}$, bacteria are faced with the problem of iron-deficient conditions due to fast oxidation of $\mathrm{Fe}$ (II) to $\mathrm{Fe}(\mathrm{III})$, causing the insolubility of Fe(III). Therefore, to overcome these barriers many bacteria can produce specific low molecular 
weight iron (III) chelators named siderophores, to sequester and solubilize iron (Fig. 1) (Chu et al. 2010; Glick et al. 2010; Hider and Kong 2010; Schalk et al. 2011; Chatterjee and O'Brian 2018).

Both Gram-positive and Gram-negative bacteria produce siderophores under iron-deprived conditions (Neilands 1995; Krewulak and Vogel 2008; Chu et al. 2010). Fe(III)-siderophore complexes bind to highly specific receptor proteins. Then, they are transported into the cytoplasm, which is different for Gram-positive and Gram-negative bacteria (Fukushima et al. 2013). While Gram-positive bacteria just have a single membrane, Gram-negative bacteria have inner and outer membranes separated by a periplasmic space (Ahmed and Holmstrom 2014). The mechanisms for trafficking of siderophores are significantly different between Gram-positive and Gram-negative bacteria, as shown in Fig. 2.

\section{Antimicrobial applications of siderophores}

Siderophore iron uptake systems are recognized as a promising antimicrobial approach due their crucial role for bacterial survival and pathogenicity (Miethke and Marahiel 2007). One of the most important applications of these systems is selective drug delivery, a Trojan Horse strategy, mainly focused in antibiotic-resistant bacteria. Several factors can dramatically upsurge bacterial resistance, including the outer membrane permeability barrier, target alteration and drug inactivating enzymes (Ferreras et al. 2005; Miller et al. 2009). This strategy can help overcoming membrane-mediated resistance in which siderophores can act as transport vectors of drugs to the inner parts of the cell. In addition, other different approaches such as inhibition of siderophore biosynthesis and iron starvation via competitive chelation are strategies of potential relevance (Ferreras et al. 2005; Miller et al. 2009).

\section{Siderophore-mediated drug delivery}

Siderophores are especially valuable to circumvent membrane-associated drug resistance using their iron transport capacity to bring drugs into cells by conjugates of siderophores and antimicrobials by the Trojan Horse approach (Miller et al. 2009; Mollmann et al. 2009). The drug that is unable to cross the bacterial membrane barrier is linked to a siderophore. Then, the Fe(III)-siderophore complex is recognized by the cognate receptor and transported across the outer membrane with the drug attached (Roosenberg et al. 2000; Miller et al. 2009; Mollmann et al. 2009). Siderophore-drug conjugates are constituted by four components: iron; a siderophore for iron binding; a linker for attaching the drug to the siderophore; and the drug (Fig. 3). All the components serve a vital function. When the siderophore-drug conjugate reaches the cytoplasm, the microorganism may be killed by several means: drug release; action as a whole antibacterial agent; blocking of iron assimilation (Ding et al. 2008; Miller et al. 2009; Mollmann et al. 2009).

Bacteria have siderophore receptor proteins that precisely recognize the iron complexes of their native siderophores, and as first approach these natural siderophores coupled to antibiotics have been used as proof of concept. Some of these naturally occurring siderophore-antibiotic conjugates, recognized as sideromycins, include salmycins, ferrimycin
Fig. 1 Siderophore-mediated iron uptake by bacteria. Under iron restriction, many bacteria can produce specific low molecular weight iron (III) chelators named siderophores, to sequester and solubilize iron (Chu et al. 2010; Glick et al. 2010; Hider and Kong 2010; Schalk et al. 2011)
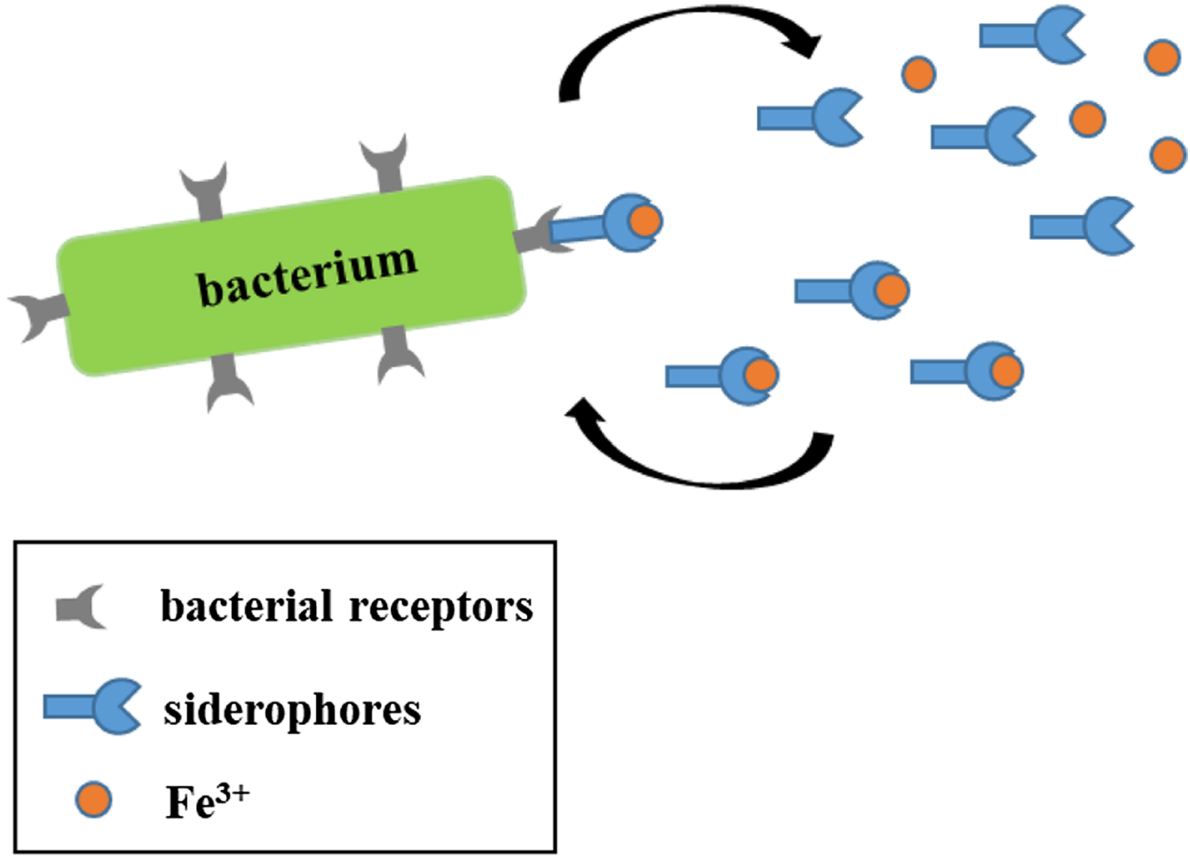


\section{GRAM-POSITIVE}

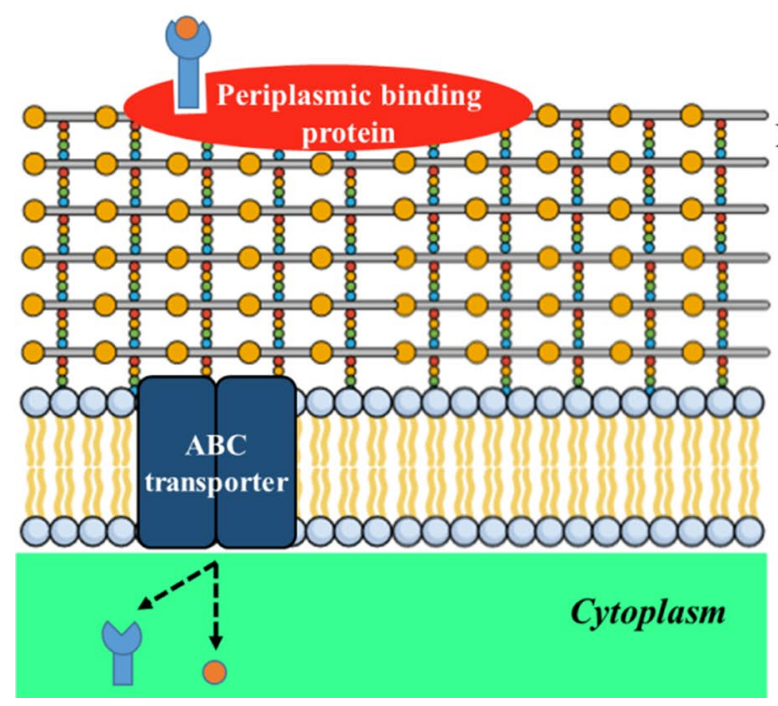

GRAM-NEGATIVE

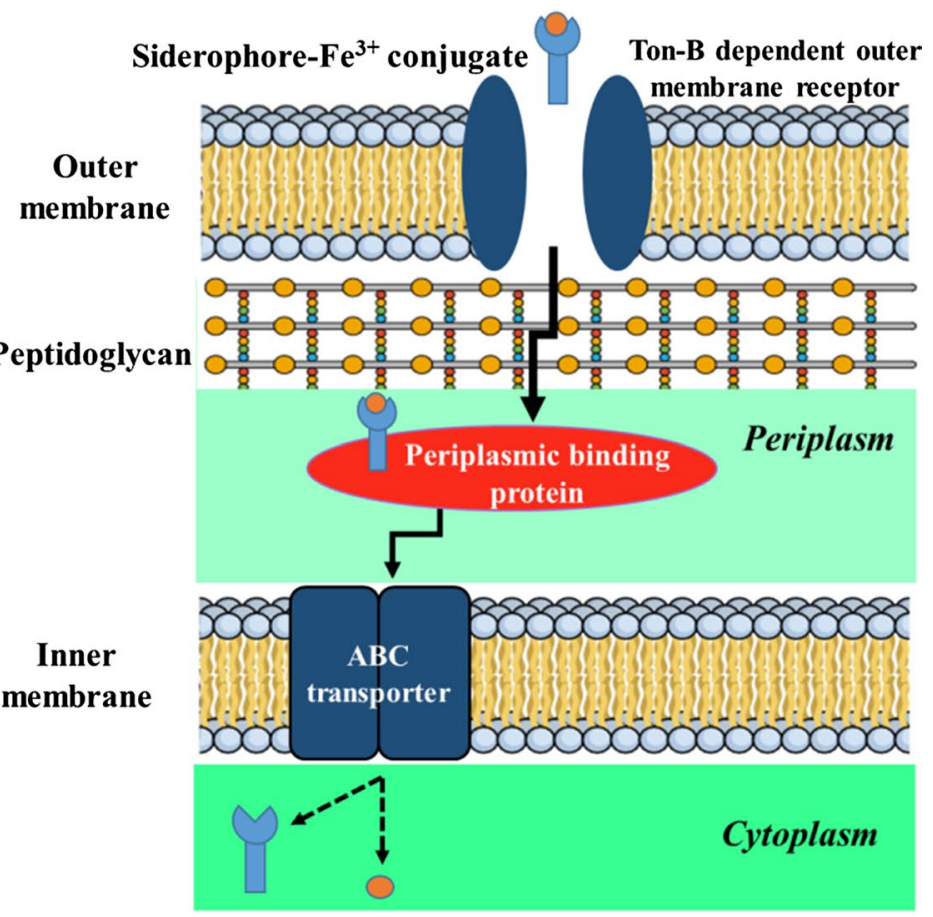

Fig. 2 Siderophore trafficking in Gram-positive and Gram-negative bacteria. In Gram-positive bacteria, due to the absence of a periplasmic space, $\mathrm{Fe}$ (III)-siderophore complexes are bound by periplasmic siderophore-binding proteins, which are anchored to the cell membrane (Krewulak and Vogel 2008; Chu et al. 2010; Fukushima et al. 2013; Ellermann and Arthur 2017). Then, the complex is transported through ATP-dependent transporters to the cytoplasm according to the ATP-binding cassette transport systems (Chu et al. 2010; Fukushima et al. 2013; Ellermann and Arthur 2017). In Gram-negative bacteria, the process in the cytoplasmic membrane is similar. However, iron uptake in these cells is more complicated due to the presence of an additional lipid bilayer-the outer membrane (Ahmed and Holmstrom 2014). This outer membrane is essential to provide improved resistance to antibiotics, detergents, degradative enzymes and host-defense proteins (Faraldo-Gomez and Sansom 2003). Nevertheless, this outer membrane forms a permeable barrier for large nutrients, preventing their transport into the cytoplasm. The transport of small nutrients, like amino acids or glucose, across the membrane is typically mediated by small pores present in the outer membranes
(Faraldo-Gomez and Sansom 2003; Krewulak and Vogel 2008; Chu et al. 2010). Nevertheless, for ferric-siderophores and other large nutrients these transport systems are insufficient, requiring their own outer membrane transporters (Krewulak and Vogel 2008; Chu et al. 2010). Gram-negative bacteria have Ton-B-dependent outer membrane receptors able to identify the $\mathrm{Fe}(\mathrm{III})$-siderophore complexes (Krewulak and Vogel 2008; Ahmed and Holmstrom 2014). After the binding of the $\mathrm{Fe}(\mathrm{III})-$ siderophore complex to the outer membrane receptor, it crosses the membrane by an energy-dependent system, which comprises the outer membrane receptor proteins, periplasmic binding proteins and inner membrane transport proteins (FaraldoGomez and Sansom 2003; Krewulak and Vogel 2008). Subsequently, this complex, which is bound by a high-affinity periplasmic binding protein, is released into the periplasmic space, transported across the cytoplasmic membrane through an ATP-binding cassette transport system, and finally, it reaches the cytoplasm (Fig. 2) (Faraldo-Gomez and Sansom 2003; Krewulak and Vogel 2008; Noinaj et al. 2010; Ahmed and Holmstrom 2014)

infection models (Braun et al. 2009). Likewise, salimycins have a trihydroxamate siderophore linked to an aminoglycoside antibiotic through a dicarboxylic acid (Braun et al. 2009). Salimycins have shown strong and selective antibacterial activity against Gram-positive bacteria, even against antibiotic-resistant strains (Braun et al. 2009). Similar to albomycins, this potent antibacterial effect is due to active transport of the salmycins through hydroxamate siderophore membrane transport proteins (Bunet et al. 2006). Ferrimycin, another naturally occurring sideromycin, has attached a moiety with antibiotic activity to ferrioxamine B by an amide link (Pramanik and Braun 2006). 


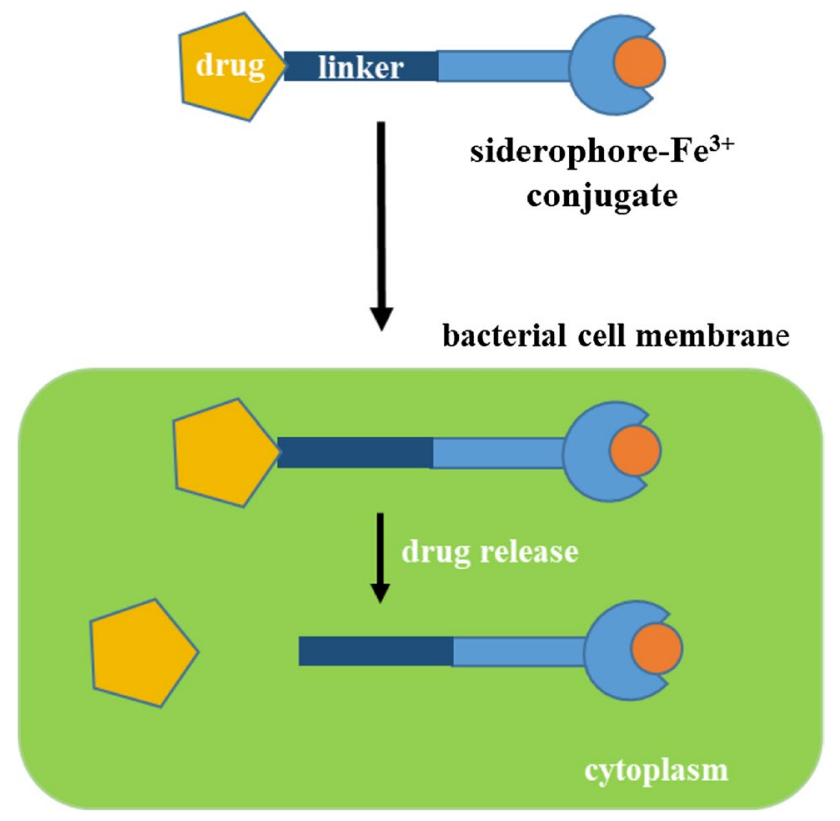

Fig. 3 The Trojan Horse strategy. Siderophore-drug conjugates are constituted by four components consisting of iron, a siderophore for binding the iron, a linker for attaching the drug to the siderophore, and the drug

The occurrence of natural siderophore-antibiotic has opened the way to produce synthetic Trojan Horses. A series of synthetic siderophore-drug conjugates have been designed, synthesized and biologically evaluated. A conjugate consisting of a mixed ligand catechol-hydroxamate siderophore linked to Loracarbef, a synthetic $\beta$-lactam antibiotic of the carbacephem class for oral administration, presented a 2000-fold increase in antibacterial action (Ghosh et al. 1996). Functionalized enterobactin- $\beta$-lactam conjugates were synthesized and exhibited a1000-fold increase in the antibacterial activity (Zheng and Nolan 2014). A conjugate composed by a hydroxypyridinone-based iron chelator and a monosulfactam antimicrobial, currently undergoing clinical trials, has presented powerful action against several Gram-negative bacteria (Page et al. 2010; Russo et al. 2011). An interesting point is that this approach can also be used to adapt antibiotics only active against Gram-positive bacteria for an uptake into the periplasm of Gram-negative bacteria. Ghosh et al. (2017) designed and synthesized a novel conjugate based on daptomycin and a mixed ligand analog of the natural Acinetobacter baumannii selective siderophore, to actively transport daptomycin into Gram-negative bacteria. Daptomycin is an antibiotic exclusively active against Grampositive bacteria as its large size and polyanionic character unable penetration through Gram-negative bacterial outer membranes. These authors observed that the resulting conjugate presented potent activity against multidrug-resistant strains of $A$. baumannii both in vitro and in vivo, even the antibiotic being larger than the transporting siderophore component circumventing the normal permeability complications in Gram-negative bacteria (Ghosh et al. 2017).

Although catecholate and hydroxamate siderophores have been used as antimicrobials delivery vehicles, carboxylate siderophores, as, for instance, staphyloferrin A, can be an effective choice in topical applications. This siderophore type exhibited improved iron chelating properties in acidic environments when compared to catecholate and hydroxamate siderophores (Milner et al. 2013; Saha et al. 2016). The hydrophilic characteristic of staphyloferrin A enhances water solubility of its conjugates and improves the drug transport rate to the bacterial cell (Milner et al. 2013; Saha et al. 2016). Several staphyloferrin-based Trojan Horse conjugates have been synthesized, and their antimicrobial properties were assessed (Milner et al. 2013).

In general, the Trojan Horse strategy using siderophore uptake pathways has been emerging as a promising approach to fight antimicrobial resistance. Moreover, the large variety in siderophores chemical structures allows to obtain a valuable chemical collection for the development of specific siderophore-antibiotic conjugates (Schalk and Mislin 2017).

Siderophore-Trojan Horse systems have also been used as a medical diagnostic tool. Early and accurate diagnosis is a crucial factor for successful therapy, underlining the pressing need for precise and sensitive diagnostic tools. Nevertheless, current diagnostic methods like computer tomography and laboratory tests possess some limitations, particularly in sensitivity and specificity (Signore and Glaudemans 2011; Auletta et al. 2016; Mills et al. 2016; Petrik et al. 2017). Molecular imaging procedures can offer a more robust, noninvasive, selective and sensitive diagnosis for infections diseases, improving clinical decisions and outcomes (Signore and Glaudemans 2011; Auletta et al. 2016; Mills et al. 2016; Petrik et al. 2017). Siderophores in Trojan Horse systems can be used for diagnosis in such a way that siderophores are not meant to target and kill bacteria but as a vehicle (Noël et al. 2011; Szebesczyk et al. 2016). A siderophore-diagnostic probe conjugate is composed by the siderophore, which will transport the diagnosis probe to target the bacterial cell without affecting mammalian cells. This happens because siderophore biosynthesis and uptake systems in mammalian cells are absent (Szebesczyk et al. 2016). The preparation of labeled siderophores can be made by the insertion of the radiometal to the natural iron-siderophore complex through the exchange of iron or artificially by the alteration of the natural siderophore with a chromophore appropriate for optical imaging (Ouchetto et al. 2005; Petrik et al. 2017). Radiolabeled siderophores may be highly specific means for infection imaging in which the energy-dependent active uptake of siderophores allows their accumulation in the tissue of interest, with the advantage that these siderophores are not used by mammals (Szebesczyk et al. 2016; Petrik et al. 
2017). Furthermore, the low molecular weight of siderophores as well as their hydrophilic character allows rapid diffusion from the circulation into infected tissues and at same time rapid clearance from nontarget tissue and elimination via renal excretion (Petrik et al. 2018). Petrick et al. (2012) used triacetylfusarinine (TAFC) and ferrioxamine E (FOXE) labeled with ${ }^{68} \mathrm{Ga}$ for the imaging of invasive pulmonary aspergillosis caused by Aspergillus fumigatus. Ga-68 is a positron emitter with comparable physicochemical properties to those of iron (III) and binds with high affinity to several siderophores (Petrik et al. 2012). It was observed that in normal mice $\left({ }^{68}\right) \mathrm{Ga}$-TAFC and $\left({ }^{68}\right) \mathrm{Ga}$-FOXE presented rapid renal excretion with high metabolic stability. In the rat infection model, both $\left({ }^{68}\right) \mathrm{Ga}-\mathrm{TAFC}$ and $\left({ }^{68}\right) \mathrm{Ga}$-FOXE showed highly selective accumulation in infected lung tissue and good correlation with severity of the infection (Petrik et al. 2012). More recently, Petrick el at (2018) evaluated pyoverdine PAO1 (PVD-PAO1), a siderophore secreted by Pseudomonas aeruginosa, radiolabeled with $\mathrm{Ga}-68$ for specific imaging of $P$. aeruginosa infections, which is an increasingly prevalent opportunistic pathogen associated with a diversity of life-threatening nosocomial infections, using positron emission tomography (PET). ${ }^{68} \mathrm{Ga}-\mathrm{PVD}-$ PAO1 presented hydrophilic properties, low protein binding and high stability in human serum. These authors observed through in vitro studies that ${ }^{68} \mathrm{Ga}$-PVD-PAO1 uptake was highly dependent on the type of microorganism. In in vivo assays, ${ }^{68} \mathrm{Ga}$-PVD-PAO1 showed excellent pharmacokinetic properties with rapid renal elimination from nontarget tissue, great specific accumulation in infected tissues and high sensitivity allowing to detect Pseudomonas infection. Furthermore, PET imaging in infected animal models showed better distribution of ${ }^{68} \mathrm{Ga}-\mathrm{PVD}-\mathrm{PAO} 1$ compared to radiopharmaceuticals clinically used: ${ }^{18} \mathrm{~F}$-fluorodeoxyglucose and ${ }^{68} \mathrm{Ga}$-citrate (Petrick et al. 2018).

\section{Inhibition of siderophore biosynthesis}

Siderophore biosynthesis may be inhibited through compounds that have the capacity to prevent bacterial growth under iron-limiting conditions (Cornelis 2010; Youard et al. 2011; Lamb 2015). Bacteria that have acquired numerous iron acquisition routes may be more resistant to antimicrobial agents that were developed to fight a single siderophore system. $P$. aeruginosa is an example of a bacterium possessing molecular mechanisms to synthesize two siderophores: pyoverdine (extremely effective but metabolically expensive) and pyochelin (not efficient but metabolically inexpensive) (Cornelis 2010; Youard et al. 2011; Dumas et al. 2013; Lamb 2015). Pyoverdine may be an interesting target for antivirulence compounds as this is critically involved in bacterial virulence (Visca et al. 2007; Kang and Kirienko 2017). The PvdS factor is responsible for expression of pyoverdine biosynthesis genes when iron is limiting, and also promotes the expression of key virulence factors, including exoproteases and exotoxin A (Imperi et al. 2013; Granato and Kümmerli 2017). Flucytosine, a synthetic fluorinated pyrimidine, is shown to have an essential role in the inhibition of $p v d S$ gene expression, triggering down-regulation of virulence genes including these involved in pyoverdine biosynthesis (Imperi et al. 2013).

Staphylococcus aureus is recognized as one of the major nosocomial human pathogens and is known to produce two citrate-based siderophores, staphyloferrin A and staphyloferrin B. Staphyloferrin B appear to have a more critical role for survival under iron-deprived conditions (Dale et al. 2004; Cheung et al. 2012; Miao et al. 2017). The biosynthesis inactivation of this siderophore reduced $S$. aureus virulence in a mouse infection model (Dale et al. 2004).

Baulamycin A and baulamycin B, two molecules extracted from the filamentous bacterium Streptomyces tempisquensis, presented high ability for siderophore biosynthesis inhibition in numerous bacteria, including some Gram-negative and Gram-positive pathogens (Tripathi et al. 2014).

\section{Iron starvation via competitive chelation}

Biofilms are the leading example of antimicrobial resistance, and biofilm formation and development are strongly dependent on iron availability (Simões 2011; Banin et al. 2006). Therefore, iron chelation may be an encouraging and novel approach to control biofilms. Non-metabolizable iron chelators can diminish iron available for microbial growth and biofilm setup (Raymond et al. 2003; Wandersman and Delepelaire 2004; Moreau-Marquis et al. 2009). Through host proteins, including transferrin, lactoferrin or ferritin, which act as iron chelators, the natural host defenses maintain a low level of existing circulating iron inside microorganisms (Raymond et al. 2003; Wandersman and Delepelaire 2004; Moreau-Marquis et al. 2009).

Very effective chelators may deprive pathogenic microorganisms from the iron essential for growth. Thus, iron chelators can be used as therapeutic compounds. Numerous compounds have been subject of study to evaluate their ability to avoid biofilm formation or disrupt established biofilms on abiotic surfaces. The iron-binding protein lactoferrin, present in airway secretions, was able to inhibit $P$. aeruginosa biofilm formation (Singh et al. 2002). The metal chelator EDTA, disodium salt of ethylenediaminetetraacetic acid, is recognized to have antimicrobial action against biofilms of Gram-positive pathogens ( Raad et al. 2003), being also a potent disruptor of $P$. aeruginosa biofilms (Banin et al. 2006). It was also observed that the combination of tobramycin, the main antibiotic used to treat cystic fibrosis lung infections, with deferoxamine or 
deferasirox, two FDA-approved iron chelators, reduced established biofilm biomass and prevented $P$. aeruginosa biofilm formation on cystic fibrosis airway cells. Furthermore, it was observed that none of these three compounds alone presented such a pronounced effect, suggesting that the combination of tobramycin and deferoxamine or deferasirox may be a good strategy to treat patients with cystic fibrosis as well as other lung diseases (MoreauMarquis et al. 2009).

It has also been known that gallium, due to its chemical similarities to iron, can replace iron in several biological systems and disrupt iron-dependent processes (Kaneko et al. 2007). Unlike Fe(III), Ga(III) cannot be reduced. Therefore, disrupting bacterial iron metabolism by gallium can lead to biofilm control (Banin et al. 2008; Bonchi et al. 2014). The mode of action of gallium is based on the decrease in bacterial iron uptake and the interference with iron signaling by the $p v d S$ gene (Kaneko et al. 2007). Antimicrobial effects have been also observed against multidrug-resistant isolates of A. baumannii, which is considered one of the most resistant pathogens among Gram-negative bacteria (Peleg and Hooper 2010; Antunes et al. 2012; de Leseleuc et al. 2012). It was demonstrated that gallium (III) exerted a strong in vitro and in vivo activity against $A$. baumannii, suppressing the growth of genotypically diverse multidrug-resistant $A$. baumannii strains. The inhibitory effect of gallium (III) was counteracted by iron, showing that gallium (III) in A. baumannii acts in the disruption of iron metabolism (Antunes et al. 2012). Olakanmi et al. (2013) assessed the ability of gallium administration to inhibit Mycobacterium tuberculosis growth in vivo using murine models of pulmonary tuberculosis infection. The authors observed inhibition of $M$. tuberculosis growth and consequently a significantly increased survival rate in gallium-treated mice (Olakanmi et al. 2013).

The similarities between gallium and iron allow it to bind to specific iron-binding proteins. This gallium-iron competition in biological systems is relevant for antimicrobial purposes. Nevertheless, it is important to take in account its toxic effects on mammalian cells (Chitambar 2016). In the work developed by Olakanmi et al. (2013), the concentration of gallium administered was considered safe for use in mammalian cells. $\mathrm{Ga}\left(\mathrm{NO}_{3}\right)_{3}$ is a FDA-approved formulation of gallium for use in humans, presenting an established safety prolife (Olakanmi et al. 2013). Qiu et al. (2014) evaluated the cytotoxicity of titanium-gallium alloys containing $10 \%$ of gallium on L929 fibroblasts and MG63 osteosarcoma cells and observed no significant toxic effects (Qiu et al. 2014). A study based on the development of a nanocomposite consisting of hydroxyapatite and gallium nanoparticles showed strong antibacterial properties against $P$. aeruginosa and low in vitro cytotoxicity for human lung fibroblasts (Kurtjak et al. 2016).

\section{Other applications of siderophores}

Siderophores can also be used in the treatment of numerous diseases, such as scavenging of iron in rapidly proliferation cancerous cells for cancer therapy, malaria disease, as well as for vaccine development (Ba et al. 2011; Miller et al. 2011; Mike et al. 2016; Khan et al. 2018).

\section{Cancer therapy using siderophores}

The iron chelation ability of siderophores is being recently explored as a therapeutic option against cancer. It is well known that high proliferative cancer cells require higher iron concentrations than normal cells for their growth (Gokarn et al. 2017; Khan et al. 2018). The association of increased iron load with several human cancer types may be due to numerous mechanisms including catalyzing the formation of mutagenic hydroxyl radicals, regulating DNA replication, repair and cell cycle progression, affecting signal transduction in cancer cells, and acting as a vital nutrient for proliferating these cells (Zhang and Zhang 2015). Numerous studies have been developed exploring the role of iron and cancer, particularly in breast cancer (Jiang et al. 2010), ovarian cancer (Basuli et al. 2017), colorectal cancer (Brookes et al. 2006), prostate cancer (Choi et al. 2008), bladder cancer (Torti et al. 1998), hepatocellular cancer (Ba et al. 2011), melanoma (Whitnall et al. 2006) and hematological malignancies (Noulsri et al. 2009; Song et al. 2011). Ba et al. (2011) found that iron deprivation by a thiosemicarbazone-24 (TSC24) iron chelator suppressed human hepatocellular carcinoma tumor growth by disrupting iron homeostasis, reducing available iron and triggering cell cycle arrest and apoptosis without any apparent host toxicity (Ba et al. 2011). Several iron chelators are currently being tested in preclinical and clinical studies as anticancer agents such as Triapine (3-aminopyridine-2-carboxaldehyde thiosemicarbazone) (Gojo et al. 2007), deferoxamine (Yamasaki and Terai 2011) and deferasirox (Lui et al. 2013). Deferasirox was reported to induce a complete remission in a patient suffering chemotherapy-resistant acute monocytic leukemia, indicating that this iron chelator may have an effective antileukemic effect (Fukushima et al. 2011).

\section{Antimalarial and antituberculosis activity of siderophores}

Tuberculosis and malaria are the two most prevalent and deadly infectious diseases occurring in the world, where around one-third of the world's population is currently infected with the causative pathogen of tuberculosis, Mycobacterium tuberculosis, and $40 \%$ is affected by malaria (Miller et al. 2011; Zumla et al. 2016). Current therapeutic treatments of both tuberculosis and malaria are ineffective (Miller et al. 2011). However, some siderophores have been 
found to be effective in the treatment of malaria, representing a potential approach for drug development. Miller et al. (2011) demonstrated that a conjugate of artemisinin, which itself is not active against tuberculosis, and a mycobacterial-specific siderophore analogue induced a significant and selective antituberculosis action and potent antimalarial activity (Miller et al. 2011).

\section{Siderophores as vaccines}

Other potential medical application of siderophores is based on the development of vaccines, a viable option to prevent and/or treat multidrug-resistant infections, in which the rates of antibiotic resistance have progressively risen over the past few decades. One of these paradigms are the urinary tract infections (UTIs), where half of all women experience a symptomatic UTI in their lifetime and are routinely treated with antibiotic therapy, including trimethroprim-sulfamethoxazole (TMP-SMX) and ciprofloxacin (Barber et al. 2013; Mike et al. 2016). Mike et al. (2016) investigated the potential of siderophores as protective vaccine antigens. For that, the authors immunized mice with siderophores conjugated to an immunogenic carrier protein and found that the siderophore-protein conjugates caused an adaptive immune response that targeted bacterial stealth siderophores and protected against UTI (Mike et al. 2016).

\section{Conclusion}

We are facing a scenario where the current arsenal of antibiotics is no longer effective. Therefore, novel treatment options are required in a post-antibiotic era. Targeting iron metabolism has been demonstrating potential in controlling bacterial growth. This metal is essential for bacterial survival, being in some cases a major virulence factor throughout the establishment of an infection. To date, three main strategies have been evaluated on the interference with several levels of bacterial iron metabolism. The Trojan Horse approach using siderophores has the capacity to deliver antibacterial drugs inside the cells, overcoming permeability-related resistance through the delivery of the drug via the iron uptake systems. The use of inhibitors of siderophore biosynthesis also holds considerable potential as an antimicrobial approach, preventing bacterial growth under iron-limited conditions. The use of iron chelators to decrease iron availability may be another effective strategy. The potential of exploiting siderophore machinery for the treatment of many other diseases also represents a promising avenue for their use as therapeutic agents.

Acknowledgements This work was the result of the projects: POCI01-0145-FEDER-030219; POCI-01-145-FEDER-006939 (Laboratory for Process Engineering, Environment, Biotechnology and EnergyUID/EQU/00511/2013) funded by the European Regional Development Fund (ERDF), through COMPETE2020 - Programa Operacional Competitividade e Internacionalização (POCI), and by national funds, through FCT-Fundação para a Ciência e a Tecnologia. NORTE-010145-FEDER-000005-LEPABE-2-ECO-INNOVATION, supported by North Portugal Regional Operational Program (NORTE 2020), under the Portugal 2020 Partnership Agreement, through the European Regional Development Fund (ERDF). The work was undertaken as part of the COST Mutalig CA15135.

\section{References}

Ahmed E, Holmstrom SJ (2014) Siderophores in environmental research: roles and applications. Microb Biotechnol 7:196-208. https://doi.org/10.1111/1751-7915.12117

Andersson DI, Hughes D (2011) Persistence of antibiotic resistance in bacterial populations. FEMS Microbiol Rev 35:901-911. https:// doi.org/10.1111/j.1574-6976.2011.00289.x

Antunes LC, Imperi F, Minandri F, Visca P (2012) In vitro and in vivo antimicrobial activities of gallium nitrate against multidrugresistant Acinetobacter baumannii. Antimicrob Agents Chemother 56:5961-5970. https://doi.org/10.1128/aac.01519-12

Auletta S, Galli F, Lauri C, Martinelli D, Santino I, Signore A (2016) Imaging bacteria with radiolabelled quinolones, cephalosporins and siderophores for imaging infection: a systematic review. Clin Transl Imaging 4:229-252. https://doi.org/10.1007/s4033 6-016-0185-8

Ba Q, Hao M, Huang H, Hou J, Ge S, Zhang Z, Yin J, Chu R, Jiang H, Wang F, Chen K, Liu H (2011) Wang H (2011) Iron deprivation suppresses hepatocellular carcinoma growth in experimental studies. Clin Cancer Res 17:7625-7633

Banin E, Brady KM, Greenberg EP (2006) Chelator-induced dispersal and killing of Pseudomonas aeruginosa cells in a biofilm. Appl Environ Microbiol 72:2064-2069. https://doi.org/10.1128/ aem.72.3.2064-2069.2006

Banin E, Lozinski A, Brady KM, Berenshtein E, Butterfield PW, Moshe M, Chevion M, Greenberg EP, Banin E (2008) The potential of desferrioxamine-gallium as an anti-Pseudomonas therapeutic agent. Proc Natl Acad Sci USA 105:16761-16766. https://doi. org/10.1073/pnas.0808608105

Barber AE, Norton JP, Spivak AM, Mulvey MA (2013) Urinary tract infections: current and emerging management strategies. Clin Infect Dis 57:719-724. https://doi.org/10.1093/cid/cit284

Basuli D, Tesfay L, Deng Z, Paul B, Yamamoto Y, Ning G, Xian W, McKeon F, Lynch M, Crum CP, Hegde P, Brewer M, Wang X, Miller LD, Dyment N, Torti FM, Torti SV (2017) Iron addiction: a novel therapeutic target in ovarian cancer. Oncogene 36:40894099. https://doi.org/10.1038/onc.2017.11

Bonchi C, Imperi F, Minandri F, Visca P, Frangipani E (2014) Repurposing of gallium-based drugs for antibacterial therapy. BioFactors 40:303-312. https://doi.org/10.1002/biof.1159

Braun V, Pramanik A, Gwinner T, Köberle M, Bohn E (2009) Sideromycins: tools and antibiotics. Biometals 22:3. https://doi. org/10.1007/s10534-008-9199-7

Brookes MJ, Hughes S, Turner FE, Reynolds G, Sharma N, Ismail T, Berx G, McKie AT, Hotchin N, Anderson GJ, Iqbal T, Tselepis C (2006) Modulation of iron transport proteins in human colorectal carcinogenesis. Gut 55:1449-1460. https://doi.org/10.1136/ gut.2006.094060

Bunet R, Brock A, Rexer HU, Takano E (2006) Identification of genes involved in siderophore transport in Streptomyces coelicolor A3(2). FEMS Microbiol Lett 262:57-64. https://doi.org/10.111 1/j.1574-6968.2006.00362.x 
Chatterjee A, O'Brian MR (2018) Rapid evolution of a bacterial iron acquisition system. Mol Microbiol. https://doi.org/10.1111/ mmi.13918

Cheung J, Murphy ME, Heinrichs DE (2012) Discovery of an ironregulated citrate synthase in Staphylococcus aureus. Chem Biol 19:1568-1578. https://doi.org/10.1016/j.chembiol.2012.10.003

Chitambar CR (2016) Gallium and its competing roles with iron in biological systems. Biochim Biophys Acta 1863:2044-2053. https://doi.org/10.1016/j.bbamcr.2016.04.027

Choi JY, Neuhouser ML, Barnett MJ, Hong CC, Kristal AR, Thornquist MD, King IB, Goodman GE, Ambrosone CB (2008) Iron intake, oxidative stress-related genes (MnSOD and MPO) and prostate cancer risk in CARET cohort. Carcinogenesis 29:964970. https://doi.org/10.1093/carcin/bgn056

Chu BC, Garcia-Herrero A, Johanson TH, Krewulak KD, Lau CK, Peacock RS, Slavinskaya Z, Vogel HJ (2010) Siderophore uptake in bacteria and the battle for iron with the host; a bird's eye view. Biometals 23:601-611. https://doi.org/10.1007/s1053 4-010-9361-x

Cornelis P (2010) Iron uptake and metabolism in pseudomonads. Appl Microbiol Biotechnol 86:1637-1645. https://doi. org/10.1007/s00253-010-2550-2

Dale SE, Doherty-Kirby A, Lajoie G, Heinrichs DE (2004) Role of siderophore biosynthesis in virulence of Staphylococcus aureus: identification and characterization of genes involved in production of a siderophore. Infect Immun 72:29-37. https:// doi.org/10.1128/iai.72.1.29-37.2004

de Leseleuc L, Harris G, KuoLee R, Chen W (2012) In vitro and in vivo biological activities of iron chelators and gallium nitrate against Acinetobacter baumannii. Antimicrob Agents Chemother 56:5397-5400. https://doi.org/10.1128/aac.00778-12

Ding P, Schous CE, Miller MJ (2008) Design and synthesis of a novel protected mixed ligand siderophore. Tetrahedron Lett 49:2306-2310. https://doi.org/10.1016/j.tetlet.2008.02.007

Dumas Z, Ross-Gillespie A, Kümmerli R (2013) Switching between apparently redundant iron-uptake mechanisms benefits bacteria in changeable environments. Proc Biol Sci 1:280. https://doi. org/10.1098/rspb.2013.1055

Ellermann M, Arthur JC (2017) Siderophore-mediated iron acquisition and modulation of host-bacterial interactions. Free Radic Biol Med 105:68-78. https://doi.org/10.1016/j.freeradbio med.2016.10.489

Faraldo-Gomez JD, Sansom MS (2003) Acquisition of siderophores in gram-negative bacteria. Nat Rev Mol Cell Biol 4:105-116. https://doi.org/10.1038/nrm1015

Ferguson AD, Braun V, Fiedler HP, Coulton JW, Diederichs K, Welte W (2000) Crystal structure of the antibiotic albomycin in complex with the outer membrane transporter FhuA. Protein Sci 9:956-963. https://doi.org/10.1110/ps.9.5.956

Ferreras JA, Ryu J-S, Di Lello F, Tan DS, Quadri LEN (2005) Smallmolecule inhibition of siderophore biosynthesis in Mycobacterium tuberculosis and Yersinia pestis. Nat Chem Biol 1:29-32. https://doi.org/10.1038/nchembio706

Fischbach MA, Walsh CT (2009) Antibiotics for emerging pathogens. Science 325:1089-1093. https://doi.org/10.1126/scien ce. 1176667

Fukushima T, Kawabata H, Nakamura T, Iwao H, Nakajima A, Miki M, Sakai T, Sawaki T, Fujita Y, Tanaka M, Masaki Y, Hirose Y, Umehara $H$ (2011) Iron chelation therapy with deferasirox induced complete remission in a patient with chemotherapy-resistant acute monocytic leukemia. Anticancer Res 31:1741-1744

Fukushima T, Allred BE, Sia AK, Nichiporuk R, Andersen UN, Raymond KN (2013) Gram-positive siderophore-shuttle with ironexchange from Fe-siderophore to apo-siderophore by Bacillus cereus YxeB. Proc Natl Acad Sci USA 110:13821-13826. https ://doi.org/10.1073/pnas.1304235110
Ghosh A, Ghosh M, Niu C, Malouin F, Moellmann U, Miller MJ (1996) Iron transport-mediated drug delivery using mixed-ligand siderophore-beta-lactam conjugates. Chem Biol 3:1011-1019. https://doi.org/10.1016/s1074-5521(96)90167-2

Ghosh M, Miller PA, Möllmann U, Claypool WD, Schroeder VA, Wolter WR, Suckow M, Yu H, Li S, Huang W, Zajicek J, Miller MJ (2017) Targeted antibiotic delivery: selective siderophore conjugation with daptomycin confers potent activity against multidrug resistant Acinetobacter baumannii both in vitro and in vivo. J Med Chem 60:4577-4583. https://doi.org/10.1021/acs.jmedc hem.7b00102

Glick R, Gilmour C, Tremblay J, Satanower S, Avidan O, Deziel E, Greenberg EP, Poole K, Banin E (2010) Increase in rhamnolipid synthesis under iron-limiting conditions influences surface motility and biofilm formation in Pseudomonas aeruginosa. J Bacteriol 192:2973-2980. https://doi.org/10.1128/jb.01601-09

Gojo I, Tidwell ML, Greer J, Takebe N, Seiter K, Pochron MF, Johnson B, Sznol M, Karp JE (2007) Phase I and pharmacokinetic study of Triapine, a potent ribonucleotide reductase inhibitor, in adults with advanced hematologic malignancies. Leuk Res 31:11651173. https://doi.org/10.1016/j.leukres.2007.01.004

Gokarn K, Sarangdhar V, Pal RB (2017) Effect of microbial siderophores on mammalian non-malignant and malignant cell lines. BMC Complement Altern Med 17:145. https://doi.org/10.1186/ s12906-017-1657-8

Granato ET, Kümmerli R (2017) The path to re-evolve cooperation is constrained in Pseudomonas aeruginosa. BMC Evol Biol 17:214. https://doi.org/10.1186/s12862-017-1060-6

Hider RC, Kong X (2010) Chemistry and biology of siderophores. Nat Prod Rep 27:637-657. https://doi.org/10.1039/b906679a

Imperi F, Massai F, Facchini M, Frangipani E, Visaggio D, Leoni L, Bragonzi A, Visca P (2013) Repurposing the antimycotic drug flucytosine for suppression of Pseudomonas aeruginosa pathogenicity. Proc Natl Acad Sci USA 110:7458-7463. https://doi. org/10.1073/pnas.1222706110

Javvadi S, Pandey SS, Mishra A, Pradhan BB, Chatterjee S (2018) Bacterial cyclic $\beta-(1,2)$-glucans sequester iron to protect against iron-induced toxicity. EMBO Rep 19:172-186. https://doi. org/10.15252/embr.201744650

Jiang XP, Elliott RL, Head JF (2010) Manipulation of iron transporter genes results in the suppression of human and mouse mammary adenocarcinomas. Anticancer Res 30:759-765

Kaneko Y, Thoendel M, Olakanmi O, Britigan BE, Singh PK (2007) The transition metal gallium disrupts Pseudomonas aeruginosa iron metabolism and has antimicrobial and antibiofilm activity. $\mathbf{J}$ Clin Invest 117:877-888. https://doi.org/10.1172/jci30783

Kang D, Kirienko NV (2017) High-throughput genetic screen reveals that early attachment and biofilm formation are necessary for full Pyoverdine production by Pseudomonas aeruginosa. Front Microbiol 8:1-15. https://doi.org/10.3389/fmicb.2017.01707

Khan A, Singh P, Srivastava A (2018) Synthesis, nature and utility of universal iron chelator-Siderophore: a review. Microbiol Res 212-213:103-111. https://doi.org/10.1016/j.micres.2017.10.012

Krewulak KD, Vogel HJ (2008) Structural biology of bacterial iron uptake. Biochim Biophys Acta 1778:1781-1804. https://doi. org/10.1016/j.bbamem.2007.07.026

Kurtjak M, Vukomanovic M, Kramer L, Suvorov D (2016) Biocompatible nano-gallium/hydroxyapatite nanocomposite with antimicrobial activity. J Mater Sci Mater Med 27:170. https://doi. org/10.1007/s10856-016-5777-3

Lamb AL (2015) Breaking a pathogen's iron will: inhibiting siderophore production as an antimicrobial strategy. Biochim Biophys Acta 1854:1054-1070. https://doi.org/10.1016/j.bbapa p.2015.05.001

Lui GY, Obeidy P, Ford SJ, Tselepis C, Sharp DM, Jansson PJ, Kalinowsk DS, Kovacevic Z, Lovejoy DB, Richardson DR 
(2013) The iron chelator, deferasirox, as a novel strategy for cancer treatment: oral activity against human lung tumor xenografts and molecular mechanism of action. Mol Pharmacol 83:179-190. https://doi.org/10.1124/mol.112.081893

Miao J, Chen L, Wang J, Wang W, Chen D, Li L, Li B, Deng Y, Xu $\mathrm{Z}$ (2017) Current methodologies on genotyping for nosocomial pathogen methicillin-resistant Staphylococcus aureus (MRSA). Microb Pathog 107:17-28. https://doi.org/10.1016/j.micpa th.2017.03.010

Miethke M, Marahiel MA (2007) Siderophore-based iron acquisition and pathogen control. Microbiol Mol Biol Rev 71:413-451. https ://doi.org/10.1128/mmbr.00012-07

Mike LA, Smith SN, Summer CA, Eaton KA, Mobley HL (2016) Siderophore vaccine conjugates protect against uropathogenic Escherichia coli urinary tract infection. Proc Natl Acad Sci USA 113:13468-13473. https://doi.org/10.1073/pnas.1606324113

Miller MJ, Zhu H, Xu Y, Wu C, Walz AJ, Vergne A, Roosenberg JM, Moraski G, Minnick AA, McKee-Dolence J, Hu J, Fennell K, Kurt Dolence E, Dong L, Franzblau S, Malouin F, Möllmann U (2009) Utilization of microbial iron assimilation processes for the development of new antibiotics and inspiration for the design of new anticancer agents. Biometals 22:61-75. https://doi.org/10.1007/ s10534-008-9185-0

Miller MJ, Walz AJ, Zhu H, Wu C, Moraski G, Möllmann U, Tristani EM, Crumbliss AL, Ferdig MT, Checkley L, Edwards RL, Boshoff HI (2011) Design, synthesis, and study of a mycobactinartemisinin conjugate that has selective and potent activity against tuberculosis and malaria. J Am Chem Soc 133:2076-2079. https ://doi.org/10.1021/ja109665t

Mills B, Bradley M, Dhaliwal K (2016) Optical imaging of bacterial infections. Clin Transl Imaging 4:163-174. https://doi. org/10.1007/s40336-016-0180-0

Milner SJ, Seve A, Snelling AM, Thomas GH, Kerr KG, Routledge A, Duhme-Klair AK (2013) Staphyloferrin A as siderophorecomponent in fluoroquinolone-based Trojan horse antibiotics. Org Biomol Chem 11:3461-3468. https://doi.org/10.1039/c3ob40162f

Mollmann U, Heinisch L, Bauernfeind A, Kohler T, Ankel-Fuchs D (2009) Siderophores as drug delivery agents: application of the "Trojan Horse" strategy. Biometals 22:615-624. https://doi. org/10.1007/s10534-009-9219-2

Moreau-Marquis S, O'Toole GA, Stanton BA (2009) Tobramycin and FDA-approved iron chelators eliminate Pseudomonas aeruginosa biofilms on cystic fibrosis cells. Am J Respir Cell Mol Biol 41:305-313. https://doi.org/10.1165/rcmb.2008-0299oc

Neilands JB (1995) Siderophores: structure and function of microbial iron transport compounds. J Biol Chem 270:26723-26726. https ://doi.org/10.1074/jbc.270.45.26723

Noël S, Guillon L, Schalk IJ, Mislin GLA (2011) Synthesis of fluorescent probes based on the Pyochelin siderophore scaffold. Org Lett 13:844-847. https://doi.org/10.1021/ol1028173

Noinaj N, Guillier M, Barnard TJ, Buchanan SK (2010) TonB-dependent transporters: regulation, structure, and function. Annu Rev Microbiol 64:43-60. https://doi.org/10.1146/annurev.micro.11240 8.134247

Noulsri E, Richardson DR, Lerdwana S, Fucharoen S, Yamagishi T, Kalinowski DS, Pattanapanyasat K (2009) Antitumor activity and mechanism of action of the iron chelator, Dp44mT, against leukemic cells. Am J Hematol 84:170-176. https://doi.org/10.1002/ ajh. 21350

Olakanmi O, Kesavalu B, Pasula R, Abdalla MY, Schlesinger LS, Britigan BE (2013) Gallium nitrate is efficacious in murine models of tuberculosis and inhibits key bacterial Fe-dependent enzymes. Antimicrob Agents Chemother 57:6074-6080. https:// doi.org/10.1128/aac.01543-13

Ouchetto H, Dias M, Mornet R, Lesuisse E, Camadro JM (2005) A new route to trihydroxamate-containing artificial siderophores and synthesis of a new fluorescent probe. Bioorg Med Chem 13:1799-1803. https://doi.org/10.1016/j.bmc.2004.11.053

Page MGP (2013) Siderophore conjugates. Ann N Y Acad Sci 1277:115-126. https://doi.org/10.1111/nyas.12024

Page MGP, Dantier C, Desarbre E (2010) In vitro properties of BAL30072, a novel siderophore sulfactam with activity against multiresistant Gram-Negative bacilli. Antimicrob Agents Chemother 54:2291-2302. https://doi.org/10.1128/aac.01525-09

Peleg AY, Hooper DC (2010) Hospital-acquired infections due to Gram-Negative bacteria. N Engl J Med 362:1804-1813. https ://doi.org/10.1056/nejmra0904124

Petrik M, Franssen GM, Haas H, Laverman P, Hörtnagl C, Schrettl M, Helbok A, Lass-Flörl C, Decristoforo C (2012) Preclinical evaluation of two $68 \mathrm{Ga}$-siderophores as potential radiopharmaceuticals for Aspergillus fumigatus infection imaging. Eur $\mathbf{J}$ Nucl Med Mol Imaging 39:1175-1183. https://doi.org/10.1007/ s00259-012-2110-3

Petrik M, Zhai C, Haas H, Decristoforo C (2017) Siderophores for molecular imaging applications. Clin Transl Imaging 5:15-27. https://doi.org/10.1007/s40336-016-0211-x

Petrik M, Umlaufova E, Raclavsky V, Palyzova A, Havlicek V, Haas H, Novy Z, Dolezal D, Hajduch M, Decristoforo C (2018) Imaging of Pseudomonas aeruginosa infection with Ga-68 labelled pyoverdine for positron emission tomography. Sci Rep 8:15698. https://doi.org/10.1038/s41598-018-33895-w

Pramanik A, Braun V (2006) Albomycin uptake via a ferric hydroxamate transport system of Streptococcus pneumoniae R6. J Bacteriol 188:3878-3886. https://doi.org/10.1128/jb.00205-06

Qiu KJ, Lin WJ, Zhou FY, Nan HQ, Wang BL, Li L, Lin JP, Zheng YF, Liu YH (2014) Ti-Ga binary alloys developed as potential dental materials. Mater Sci Eng C Mater Biol Appl 34:474-483. https://doi.org/10.1016/j.msec.2013.10.004

Raad I, Chatzinikolaou I, Chaiban G, Hanna H, Hachem R, Dvorak T, Cook G, Costerton W (2003) In vitro and ex vivo activities of minocycline and EDTA against microorganisms embedded in biofilm on catheter surfaces. Antimicrob Agents Chemother 47:3580-3585. https://doi.org/10.1128/ aac.47.11.3580-3585.2003

Raymond KN, Dertz EA, Kim SS (2003) Enterobactin: an archetype for microbial iron transport. Proc Natl Acad Sci USA 100:3584-3588. https://doi.org/10.1073/pnas.0630018100

Ribeiro M, Simões M (2019) Siderophores: a novel approach to fight antimicrobial resistance, In: Arora D, Sharma C, Jaglan S, Lichtfouse E (eds) Pharmaceuticals from microbes. Environmental Chemistry for a Sustainable World, vol 28. Springer Nature, Cham, Switzerland, pp 99-120. ISBN 978-3-030-01881-8. https ://doi.org/10.1007/978-3-030-04675-0_5

Roosenberg JM 2nd, Lin YM, Lu Y, Miller MJ (2000) Studies and syntheses of siderophores, microbial iron chelators, and analogs as potential drug delivery agents. Curr Med Chem 7:159-197. https://doi.org/10.2174/0929867003375353

Russo TA, Page MG, Beanan JM, Olson R, Hujer AM, Hujer KM, Jacobs M, Bajaksouzian S, Endimiani A, Bonomo RA (2011) In vivo and in vitro activity of the siderophore monosulfactam BAL30072 against Acinetobacter baumannii. J Antimicrob Chemother 66:867-873. https://doi.org/10.1093/jac/dkr013

Saha M, Sarkar S, Sarkar B, Sharma BK, Bhattacharjee S, Tribedi P (2016) Microbial siderophores and their potential applications: a review. Environ Sci Pollut Res Int 23:3984-3999. https://doi. org/10.1007/s11356-015-4294-0

Schalk IJ, Mislin GLA (2017) Bacterial iron uptake pathways: gates for the import of bactericide compounds. J Med Chem 60:4573-4576. https://doi.org/10.1021/acs.jmedchem.7b00554

Schalk IJ, Hannauer M, Braud A (2011) New roles for bacterial siderophores in metal transport and tolerance. Environ Microbiol 13:2844-2854. https://doi.org/10.1111/j.1462-2920.2011.02556.x 
Signore A, Glaudemans AW (2011) The molecular imaging approach to image infections and inflammation by nuclear medicine techniques. Ann Nucl Med 25:681-700. https://doi.org/10.1007/s1214 9-011-0521-z

Simões M (2011) Antimicrobial strategies effective against infectious bacterial biofilms. Curr Med Chem 18:2129-2145. https://doi. org/10.2174/092986711795656216

Singh PK, Parsek MR, Greenberg EP, Welsh MJ (2002) A component of innate immunity prevents bacterial biofilm development. Nature 417:552-555. https://doi.org/10.1038/417552a

Song S, Christova T, Perusini S, Alizadeh S, Bao RY, Miller BW, Hurren R, Jitkova Y, Gronda M, Isaac M, Joseph B, Subramaniam R, Aman A, Chau A, Hogge DE, Weir SJ, Kasper J, Schimmer AD, Al-awar R, Wrana JL (2011) Attisano L (2011) Wnt inhibitor screen reveals iron dependence of $\beta$-catenin signaling in cancers. Cancer Res 71:7628-7639. https://doi.org/10.1158/0008-5472. can-11-2745

Szebesczyk A, Olshvang E, Shanzer A, Carver PL, Gumienna-Kontecka E (2016) Harnessing the power of fungal siderophores for the imaging and treatment of human diseases. Coord Chem Rev 327-328:84-109. https://doi.org/10.1016/j.ccr.2016.05.001

Torti SV, Torti FM, Whitman SP, Brechbiel MW, Park G, Planalp RP (1998) Tumor cell cytotoxicity of a novel metal chelator. Blood 92:1384-1389

Tripathi A et al (2014) Baulamycins A and B, broad-spectrum antibiotics identified as inhibitors of siderophore biosynthesis in Staphylococcus aureus and Bacillus anthracis. J Am Chem Soc 136:1579-1586. https://doi.org/10.1021/ja4115924

Visca P, Imperi F, Lamont IL (2007) Pyoverdine siderophores: from biogenesis to biosignificance. Trends Microbiol 15:22-30. https ://doi.org/10.1016/j.tim.2006.11.004

Wandersman C, Delepelaire P (2004) Bacterial iron sources: from siderophores to hemophores. Annu Rev Microbiol 58:611-647. https://doi.org/10.1146/annurev.micro.58.030603.123811
Whitnall M, Howard J, Ponka P, Richardson DR (2006) A class of iron chelators with a wide spectrum of potent antitumor activity that overcomes resistance to chemotherapeutics. Proc Natl Acad Sci USA 103:14901-14906. https://doi.org/10.1073/pnas.0604979103

Yamasaki T, Terai S (2011) Sakaida I (2011) Deferoxamine for advanced hepatocellular carcinoma. N Engl J Med 365:576-578. https://doi.org/10.1056/nejmc1105726

Youard ZA, Wenner N, Reimmann C (2011) Iron acquisition with the natural siderophore enantiomers pyochelin and enantio-pyochelin in Pseudomonas species. Biometals 24:513-522. https://doi. org/10.1007/s10534-010-9399-9

Zhang C, Zhang F (2015) Iron homeostasis and tumorigenesis: molecular mechanisms and therapeutic opportunities. Protein Cell 6:88100. https://doi.org/10.1007/s13238-014-0119-z

Zheng T, Nolan EM (2014) Enterobactin-mediated delivery of $\beta$-lactam antibiotics enhances antibacterial activity against pathogenic Escherichia coli. J Am Chem Soc 136:9677-9691. https://doi. org/10.1021/ja503911p

Zumla A, Rao M, Wallis RS, Kaufmann SH, Rustomjee R, Mwaba P, Vilaplana C, Yeboah-Manu D, Chakaya J, Ippolito G, Azhar E, Hoelscher M, Maeurer M (2016) Host-directed therapies for infectious diseases: current status, recent progress, and future prospects. Lancet Infect Dis 16:e47-e63. https://doi.org/10.1016/ s1473-3099(16)00078-5

Publisher's Note Springer Nature remains neutral with regard to jurisdictional claims in published maps and institutional affiliations. 